November - 2009

\title{
Openness, Dynamic Specialization, and the Disaggregated Future of Higher Education
}

\author{
David Wiley and John Hilton III \\ Brigham Young University, USA
}

\begin{abstract}
Openness is a fundamental value underlying significant changes in society and is a prerequisite to changes institutions of higher education need to make in order to remain relevant to the society in which they exist. There are a number of ways institutions can be more open, including programs of open sharing of educational materials. Individual faculty can also choose to be more open without waiting for institutional programs. Increasing degrees of openness in society coupled with innovations in business strategy like dynamic specialization are enabling radical experiments in higher education and exerting increasing competitive pressure on conventional higher education institutions. No single response to the changes in the supersystem of higher education can successfully address every institution's situation. However, every institution must begin addressing openness as a core organizational value if it desires to both remain relevant to its learners and to contribute to the positive advancement of the field of higher education.
\end{abstract}

Keywords: Open education; online learning; distance learning; higher education

\section{The Changing Context of Higher Education}

Higher education is a dynamic, complex system embedded in an even more dynamic and complex supersystem - human society. Technological innovations have radically changed this supersystem in at least six ways that are critical for higher education to recognize and understand (Wiley, 2006). The degree of disconnection between higher education and its supersystem is even greater now than when Wiley first proposed these categories.

\section{From Analog to Digital}

The primary format of information capture and dissemination has changed from analog to digital. It is increasingly difficult to find music recorded on vinyl or movies recorded on VHS tapes because MP3s and DVDs have become the preferred formats for exchanging entertainment. Television stations in the US were recently required to abandon analog broadcasts in favor of 
digital broadcasts. Printed newspapers are quickly losing ground to digital, online formats of news distribution, and some newspapers have even gone out of business (McIntyre, 2009).

\section{From Tethered to Mobile}

Activities that historically tied a person to a specific place have become more spatially accommodating. Mobile phones allow us to talk to colleagues, friends, and family without being tethered to a wall by a telephone cord. Wireless devices allow us to surf the Web, Facebook, and IM without being tethered to a wall by a network cable. Advances in battery technology allow us to talk on cell phones and use laptop computers without being tethered to a wall by a power cord.

\section{From Isolated to Connected}

The drive toward universal, real-time interconnectedness defines our time better, perhaps, than any other description. While reference lists at the end of research articles once provided a genealogy of ideas in a paper, hyperlinks now directly connect papers to the sources they cite. While TCP/IP and other protocols once allowed computers to make basic connections to one another, web services and APIs allow more sophisticated types of connections between computers. Where telegrams and letters once connected people to one another asynchronously, social networks (e.g., Facebook), VOIP services (e.g., Skype), texting, and mobile phones now connect people in real-time. People are more connected to people, content is more connected to content, and systems are more connected to other systems than ever before. And permutations of connectedness, such as people to content connections (e.g., the Web), systems to content connections (e.g., the semantic web), and people to systems connections (e.g., online package tracking), are also growing exponentially as well.

\section{From Generic to Personal}

Technology enables "mass customization" of goods and services in almost every area of life. When buying a new laptop, instead of purchasing a machine off the shelf, people commonly use an online service to pick a custom amount of RAM, a custom size hard drive, and a custom size display. Upon opening the made-to-order machine, many users select a custom wallpaper image. Likewise, when mobile phones ring in a crowded public area, each plays a different ring tone selected by its owner. Interactive websites let us customize the paint color and options on cars we're interested in purchasing. And Amazon.com, a store with literally millions of customers, makes individualized personal recommendations to each and every one of its users.

\section{From Consumers to Creators}

The tools and other means necessary to produce and distribute various cultural artifacts like books, movies, and music were once the expensive, exclusive province of the wealthy. The cost barrier to producing and distributing information and culture has almost disappeared. Word processors and print-on-demand publishing services allow anyone to publish a book and compete 
with commercial publishers. Free blogging software and digital cameras commonly found in mobile phones allow anyone to become a reporter and compete with newspapers. Inexpensive video cameras and video hosting sites like YouTube allow anyone to distribute movies and compete with the big distribution houses. We no longer simply read and watch - we now write, record, and publish, too.

\section{From Closed to Open}

The economics of distributing information digitally, which make per unit distribution costs all but disappear, have enabled widespread, free sharing on a scale never before seen. The world of open source software provides users with completely free and legal replacements for the Windows operating system, Microsoft Office, Adobe Photoshop, SPSS, and other expensive software tools. Data that were once unavailable to the general public, like GIS or weather data, are now freely available in real-time or near real-time. And works that once cost hundreds or thousands of dollars, such as a set of encyclopedias or a comprehensive collection of great literature, are fully and freely available at no cost to anyone with an Internet connection.

While commercial industries have converted these technological advances into consumer benefits, thereby making customers happier and improving their own financial bottom lines, higher education has largely ignored these changes in its supersystem. In fact, rather than using headlines of "Then" and "Now," these changes can be accurately portrayed (as shown in Table 1) as the differences between higher education and the everyday lived experience of individuals in the supersystem in which higher education is embedded.

Table 1

The Differences between Higher Education and the Supersystem in which it is Embedded

\begin{tabular}{|l|l|l|}
\hline Education & Everyday \\
\hline Analog & & Digital \\
\hline Tethered & & Mobile \\
\hline Isolated & & Connected \\
\hline Generic & & Personal \\
\hline Consumers & & Creators \\
\hline Closed & Open \\
\hline
\end{tabular}


Consider the in-class experience of a typical undergraduate:

After applying for admission to the university, registering for classes, and paying tuition (universities are closed unless you're approved to enter and you can afford to pay), Jay makes his way into a large, stadium seating-style room (he is tethered to that place and time if he wants to hear the lecture). Talking during the lecture is taboo and the professor has a strict "lids down" policy to help students focus on the course material (Jay is effectively isolated because even though he is surrounded by friends and peers, and wireless Internet is available across campus, he is forbidden from drawing on these resources during class). Having read his textbook and reviewed the assigned handouts (analog materials), Jay joins 150 other students in listening to a 50-minute lecture (every student is a consumer of the same generic information regardless of their academic preparation).

Now consider Jay's experience throughout the rest of his day:

From his dorm room, the student center, a cafe, and a bus, Jay connects to the Internet via his laptop and mobile phone (he is mobile) in order to search Google for information (digital resources are open for him to freely access) relevant to tomorrow's test. Temporarily stymied, he chats with friends on the phone and by Instant Messaging (IM) to see if they can assist in his search (he is connected to other people). Finally finding a good source, he follows some links to explore related information (the content is connected to other content), ignoring material he has already mastered (reading only what is important to him personally). Later that evening at study group Jay shares his find with friends (participating in the teaching process).

The traditional distance education student suffers many of the same challenges. Consider the experience of Jane, a student at a large distance education institution.

After applying for admission to the university, registering for classes, and paying tuition (the university is closed to her unless she's approved to enter and can afford to pay), Jane waits until she receives a password and permission to enroll in the university learning management system. She is not tethered in place (as she can access the course from wherever network connection is available), but she is tethered to a strict schedule to meet the pacing constraints of the institution. Jane remains isolated even from students in the same class who may live in her neighborhood (because privacy legislation doesn't allow the university to release location information to fellow students). Although some course content is available online, copyright restrictions insure that students must purchase materials encapsulated in analog textbooks. The course content has been prepared months or even years earlier, and even the tutor assigned to evaluate her work is not allowed to change or update the course content (every student is a consumer of the same generic information regardless of their academic preparation). 
Like Jay, Jane's experience in her real life consists of access to many of the same networked resources. Despite the restrictions on access, she is able to find human and non-human resources on social networks, and by following connected links she can find updated content relevant to her course. Jane realizes she is learning material that is both interesting and relevant, but harbors a nagging fear that the material she is learning with will not be the exact knowledge that she will be tested upon on her final exam.

\section{The Daily Divide}

The well-known phrase "digital divide" describes the gulf between individuals who have access to information technology and individuals who do not have access to information technology. Like so many negative phenomena, the digital divide discriminates disproportionately against people of lower socioeconomic status.

We refer to the painful disconnection between Jay's lived experience in the real world and the artificial environment inside the classroom as the daily divide. Unlike the digital divide, the daily divide also discriminates against people of higher socioeconomic status. Individuals with abundant access to information and communication technologies who have habits of effective use of these technologies in information-seeking and problem-solving activities are unable to make effective use of these technologies in higher education settings like the class described above. They may, of course, choose to "go rogue" outside of class and draw upon modern technologies and their skills with the same in completing assignments outside of class, but this only serves to reinforce the feeling of disconnection and disorientation on in-class exams.

\section{Monopoly No More}

One may be tempted to respond, "Who cares about a daily divide? We're higher education! Without a college degree, they aren't going to get jobs. Whether we're responsive to changes in our environment or not, it's not like students are going to stop coming to our institutions." But higher education's historic monopoly is being challenged in each of its major functional areas: structuring and providing access to content, tutoring and learning support services, curating and providing access to research materials, acting as a hub for social activities, and awarding degrees and other credentials.

\section{Structuring and providing access to content.}

Universities once held a monopoly on access to expert faculty who selected appropriate content for a course of learning and structured a path through that content for learners. Since the advent of the Internet - and especially the popularization of open content - expert-selected and expertstructured content has become widely available to the public through sites like MIT's OpenCourseWare and Carnegie Mellon's Open Learning Initiative. Access to these materials, once the exclusive province of admitted, tuition-paying students is now available to everyone with Internet access. Other websites like Wikipedia and Connexions increase the amount of high 
quality material available to the public. The university's monopoly on access to educational content is gone, and in many cases (like MIT and CMU) the universities have proactively undercut this monopoly themselves.

\section{Tutoring and learning support services.}

Universities once held a monopoly on access to teachers, tutors, and others who could answer student questions and support them academically in their learning. The advent of user-contributed websites and social media has drastically altered the equation. A student with a question can now turn to a number of free services like ChaCha, an SMS-based service to which people text their questions and receive answers. (ChaCha answered over 150,000,000 questions in its first eighteen months of service [ChaCha, 2009].) Other ways students can get answers include Yahoo! Answers, an online discussion forum where millions of people ask and answer questions, and Twitter and Facebook, where questions asked in status updates generate numerous answers in comments. Some education-specific sites provide students with the support and help they need as well. NoteCentric, NoteMesh, and ShareNotes.com help students share educational materials they create with each other (e.g., notes they take during class or while reading a book). RateMyProfessor helps students decide which professors they should take classes from, which programs they should major in, and which universities they should attend. Students' informal ratings in RateMyProfessor (more than 10,000,000 ratings as of September, 2009) have been shown to correlate significantly with the formal student evaluations completed within universities (Coladarci \& Kornfield, 2007). Students do not need an academic advisor to tell them about a class - peer review can do this. The university's monopoly position in providing tutoring and other learning supports has vanished.

\section{Curating and providing access to research materials.}

The university library once held a monopoly position in collecting and providing access to highquality research materials and guarded this access carefully by only permitting students and faculty access to its collections. Today there are high-quality research journals that publish all their papers online for anyone to read at no cost. For example, the fully open access PLOS Biology had the largest impact factor in its field for 2008, according to ISI. PLOS Biology's impact factor for 2008 was 12.683, while the second place journal, Biological Reviews, had an impact factor of only 8.755. The increasing popularity of preprint archives like arXiv.org (which contains over 500,000 articles in physics, mathematics, computer science, and related areas) is also increasing individuals' free access to cutting-edge research. The university's monopoly status as provider of access to high-quality research has vanished (and in some cases, the universities themselves provide this open access to research). 


\section{Acting as a hub for social activities.}

With the explosive popularity of social networks like Facebook and MySpace, little needs to be said about students' ability to find and connect with each other without a university campus acting as a mediator.

\section{Assessing learning and awarding degrees.}

Higher education once held a monopoly on the credentials that truly established a person as an expert in his field. Traditional higher education has a number of new competitors in both the online learning space (like University of Phoenix, Walden, Capella, and others) as well as in the no-tuition or very low tuition space (like University of the People, Peer to Peer University, and others). But the threat to the monopoly traditional higher education has held on degrees comes from other areas as well. In the computer science domain, for example, technical certifications from Cisco, RedHat, Microsoft, and others can prove more valuable to prospective employees than a bachelor's degree in computer science. The university's monopoly on certifying prospective employees has expired.

Traditional higher education no longer holds a de facto monopoly in any of its primary functional areas, as it once did. Viable alternatives exist in each and every service it provides. Worse yet for higher education, we find ourselves in a world economic climate where companies as large as General Motors and AIG are going bankrupt. And while the U.S. automotive, insurance, and banking industries have received billions of dollars in bailout funding, institutions of higher education in the U.S. have suffered double-digit budget cuts.

With no monopoly position and no bailout coming, is higher education so arrogant as to really believe itself immune to what is happening in its supersystem? Higher education is left with only one choice: innovate in order to stay relevant.

\section{The Higher Education Response to Changes in its Supersystem}

While information technology has not completely revolutionized higher education, as it has other fields, we cannot accurately claim that technology has not significantly improved parts of higher education. Administrative systems and processes have significantly improved in efficiency and effectiveness as university administrative units have moved to technology-mediated systems for processing student applications, managing course registrations, dealing with financial aid, and handling payroll and benefits.

Centrally directed administrative units can make decisions to adopt technology in order to improve services and decrease costs. However, because faculty claims academic freedom and refuses to be directed by university administration (or anyone else), teaching and learning practices on campus survive largely unscathed by changes in the supersystem. 
One may be tempted to point to online classes or "e-learning" as teaching and learning's innovative response to the technological advances happening in the world outside higher education. Such a claim may have been valid in 1995 when e-learning was on the cutting edge of educational practice. However, a claim that e-learning is innovative in 2009 may be inappropriate.

As implied by phrases like "move my course online," online classes are commonly structured and conducted much like on-campus classes. Although online courses are digital and may be taken asynchronously from home or elsewhere (mobile), they are famously more isolating than oncampus courses, broadcast the same set of generic materials to all learners, who still act exclusively as consumers, and are closed behind passwords unless registration and payment demands are met. (Previous research has shown that faculty use learning management systems primarily to gain administrative efficiencies in the management of their classes and not as a means of improving teaching and learning [Mott, 2009].) While a few innovative exceptions exist, Table 2 shows that conventional online courses have only two of the six attributes we would expect from a comprehensive response to changes in higher education's supersystem.

Table 2

Characteristics of Online Classes

\begin{tabular}{|l|l|l|}
\hline \multicolumn{2}{|l|}{ Online Classes } \\
\hline Analog & & Digital \\
\hline Tethered & & Mobile \\
\hline Isolated & & Connected \\
\hline Generic & & Personal \\
\hline Consumers & & Creators \\
\hline Closed & Open \\
\hline
\end{tabular}

\section{Toward a More Appropriate Response to Changes in Higher Education's Supersystem}

An appropriate response to changes in higher education's supersystem should include increases in connectedness, personalization, participation, and openness. Of these four, a significant increase in openness is the most pressing priority for higher education because a culture of openness is a prerequisite to affordable, large-scale progress in the other three areas, as explained below. 


\section{Connecting and openness.}

When a resource or service is closed it cannot be connected to. For example, if the student from our previous examples, Jay, wants to review material from an online course he took last semester, which is located in the university's course management system, he will be sorely disappointed. He cannot reconnect with that material because he is not registered this semester, so the course is closed to him. If Jay's professor depends on her students having learned something in the previous course and would like to link them back to that material for review before launching into a new topic in her course, she will also be sorely disappointed. The potential for connectedness within higher education is related to the degree of openness within higher education.

\section{Personalizing and openness.}

While the inability to connect without openness is a technical issue, the impediments to personalizing without openness are legal in nature. Editing, adapting, or otherwise changing educational materials to be more appropriate for a specific use is technically straightforward thanks to the variety of technologies currently available. However, as nations continue to strengthen their copyright laws, acquiring permission before making these changes to traditionally copyrighted materials becomes increasingly important. While an individual faculty member may claim that making such alterations for use within his own classroom is a "Fair Use," relying on this defense neither guarantees that the use is actually fair nor allows him to share the results of his revising effort outside his classroom. On the other hand, if the instructor starts with an openly licensed educational resource, his revisions are both legal and sharable to the wider world. The potential for personalization of educational materials, an entire course or a single resource, is directly proportional to the openness of the material's license.

\section{Creating and openness.}

After the search engines, most of the top 50 sites in Alexa's ranking of the most trafficked websites in the world are sites based on the act of sharing: sharing things like videos, status updates, photographs, personal information, files, blog posts, and other media. As recently as five years ago, very few people were producing video. And without an outlet for sharing their creative works, where was the motivation for making video? The recent emergence of YouTube, Blip.tv, and other sites open to users' contributions of videos has given individuals an opportunity to share - and therefore a motivation to create - these works. A March 2008 estimate by Wesch put the number of new videos uploaded to YouTube each day near 200,000. Just as few people produced video in the early 2000 s, very few students currently produce educational materials for the classes they take. The faculty member isn't open to receiving or distributing these, and without an open outlet for these materials students have little incentive to do anything but remain passive receptacles of experts' knowledge. The degree to which people will create new works is related to the existence of open channels for the sharing of their works. 
If, as we have argued, openness is the fundamental value underlying the other changes needed in institutions of higher education, the critical question becomes, "how can an institution be more open?"

\section{Models of Openness in Higher Education ${ }^{1}$}

A number of fledgling models of "more open" institutions of higher education exist. Perhaps the best known is MIT OpenCourseWare; this project relies on dozens of professional staff to support the openly licensed publication of primarily textual materials used in teaching MIT courses (see http://ocw.mit.edu/). While the project is grand in scale (1900 courses worth of materials have been published to date) and an inspiration to institutions and universities around the world, its exorbitant costs - $\$ 4,000,000$ per year - make it a model that no other school can afford to emulate. Hundreds of other schools have begun down the OCW path, publishing a few dozen courses. Indeed, in the current economic climate we are forced to wonder about the sustainability of a $\$ 4,000,000$ program that creates no revenue for the university and is targeted primarily at offcampus users.

A variety of other iterations of the MIT OCW model exist. For example, the Open Yale Courses (see http://oyc.yale.edu/) publishes video of Yale courses, accompanied by only minimal textual materials. Webcast.Berkeley (see http://webcast.berkeley.edu/), a University of California, Berkeley open education program, provides podcasts and webcasts exclusively, with no textual material at all.

A number of universities that have significant distance learning programs have begun to use a modified version of the MIT OCW model, in which materials from courses that are available for enrollment and completion at a distance are published with open licenses. The Open University of the UK, the Open University of the Netherlands, the University of California, Irvine, and Brigham Young University Independent Study all use their OCW collections to simultaneously provide a public service and market their for-pay online courses. While studies of the financial effectiveness of this model of openness are ongoing, preliminary data indicate that these projects may be financially self-sustaining (Wiley, 2009).

The Connexions project at Rice University takes a more participatory, Wikipedia-like approach. The Connexions website (see http://cnx.org/) contains openly licensed resources that can be contributed to or edited by anyone, making for a great breadth of materials available on the site (over 14,500 modules have been published). This distinguishes Connexions from other institutional initiatives as much of the content within the collection comes from outside Rice University. As with Wikipedia, concerns regarding quality have haunted the project; consequently, a new site function called Lenses was added, which allows users to make quality assertions about resources in the collection. Whether or not the Lenses functionality impacts user beliefs about the quality of resources in the site remains to be measured and reported.

The Carnegie Mellon Open Learning Initiative takes yet another approach. CMU OLI produces a small number of openly licensed, full online courses. These courses are highly designed and are 
meant to facilitate effective learning experiences (as opposed to being simple publications of course materials). While these courses are extremely expensive to produce, they are also extremely effective in supporting student learning. A series of studies by Lovett, Meyer, and Thille (2008) demonstrated that students using the online OLI Statistics course "learned a full semester's worth of material in half as much time and performed as well or better than students learning from traditional instruction over a full semester" (p. 1). No studies yet report a comparison of potential resource savings to CMU (e.g., teaching twice as many students during a semester) with the cost of developing the courses. However, should other universities choose to use OLI courses a significant savings could be realized.

Individual faculty members who are interested in being more open do not have to wait for their institutions to launch formal initiatives. A practice known as "open teaching" is gaining ground among some faculty: see, for example, courses by Wiley (http://opencontent.org/wiki/index.php?title=Intro_Open_Ed_Syllabus), Siemens and Downes (http://ltc.umanitoba.ca/connectivism/), and Couros (http://eci831.wikispaces.com/). In open teaching, faculty publish their course materials online under an open license before the beginning of the course and invite others from outside their university to participate in the course together with the "official students" of the course. In many cases, all students (both tuition-paying and informal students) post their work to publicly accessible blogs for critique and discussion by the larger group. Fini and colleagues (2008), who were students in Wiley's 2007 course, provide a more detailed description of the course model and outcomes. Sometimes, course content and interaction is provided and mediated by wikis, sometimes blogs are used, and sometimes social networking sites like Ning or Facebook are used to host content and conversation.

In summary, a variety of models exist for both institutions and individual faculty to be dramatically more open in their teaching. The list presented above is by no means exhaustive. Because openness - properly construed - is a practice and not a project (Robertson, 2009), openness will manifest itself differently in different institutions as it becomes part of the core organizational culture.

\section{Openness and the Disaggregated Future of Higher Education}

We have argued above that openness is a critical attribute of the supersystem in which higher education is positioned and that higher education must therefore become more open to remain relevant to the society in which it exists. However, there are additional, tactical arguments to be made in favor of higher education becoming more open. Hagel and Brown (2005) argue that in the future successful businesses will rely on a strategy of "dynamic specialization."

By dynamic specialization, we mean the commitment to eliminate resources and activities that no longer differentiate the firm and to concentrate on accelerating growth from the capabilities that truly distinguish the firm in the marketplace. Consequently, firms cannot simply focus on differentiation but must also shed nondifferentiating activities. (p. 54) 
We have already posited that universities are comprised of at least five major functional areas, including structuring and providing access to content, tutoring and learning support services, curating and providing access to research materials, acting as a hub for social activities, and assessing learning and awarding degrees. According to Hegel and Brown, we should soon expect to see higher education institutions making difficult choices to focus on developing truly worldclass expertise in one or two of these functions and outsourcing the others.

Western Governor's University (see http://wgu.edu/) is one institution that follows the path outlined by Hegel and Brown. WGU is a fully accredited university that offers no courses whatsoever; instead, it has chosen to focus on assessing learning and awarding degrees. It refers students to partner institutions when they need to take a formal course or to access library collections before taking their exams.

The Open High School of Utah (see http://openhighschool.org/), described by Wiley (2009), is another example of an educational institution that employs a version of dynamic specialization. According to the OHSU mantra of "focus on learning and outsource everything else," the school has shed its business management, HR, technology support (every student is given a laptop), learning management system hosting and support, and other functions in order to concentrate on developing its "strategic tutoring" model of teaching and its "open curriculum." School employees include only the principal, teachers, a curriculum developer, and a part-time secretary. Every individual employed by the school is focused on improving learning.

Both WGU and OHSU present potential challenges to conventional education institutions that internally bundle a number of business functions, as Hegel and Brown point out:

By tightly bundling [many] businesses together, companies inevitably sub-optimze the performance of one or more of the businesses. The companies therefore become vulnerable to morefocused competitors that have chosen to focus tightly... More diversified companies that choose to retain these activities within their enterprise will face increasingly severe competition from companies that access these world-class capabilities from focused providers. (p. 55)

When world-class capabilities are not only provided but are provided freely and openly, the potential for innovation increases significantly. The increase in innovation is due to the decrease in transaction costs (specifically, bargaining costs) for those attempting to access these worldclass capabilities because open licenses (like the Creative Commons licenses, see http://creativecommons.org/) specify the terms on which the services can be accessed and used (e.g., without cost). Lower transaction costs decrease the overall cost and risk of experimenting with various innovations, thereby increasing the number of actors capable and willing to innovate. 
A number of organizations are already combining their particular business knowledge with openly available world-class educational material (like Carnegie Mellon's Open Learning Initiative courses, see http://cmu.edu/oli/) and with freely available world-class social interaction capabilities (like Facebook, see http://facebook.com/) in order to compete with traditional universities. Organizations such as Peer-to-Peer University (see http://p2pu.org/), the University of the People (see http://www.uopeople.org/), and Tech University of America (see http://www.techuofa.com/) each bring a different set of internal capabilities to their relationships with "open service providers." Open service providers are those individuals or organizations that provide access to world-class capabilities under open licenses and at lower transaction costs.

Because open service providers lower the cost and risk of educational experiments, they are a critical piece of the infrastructure necessary for enabling rapid educational innovation. It is in this sense that Wiley $(2005,2008)$ argued that "content is infrastructure," referring to the important role of open educational resources in enabling educational innovations. Educational experiments like the Open High School of Utah and the University of the People could not exist without a sufficiently broad, high-quality infrastructure of open educational resources to build upon. Put another way, they could not exist without open service providers like MIT OCW and CMU OLI.

Open service providers will be at the center of many future educational innovations due to their role in enabling rapid, inexpensive, low-risk experiments. Higher education must consider two issues in this regard. First, the availability of world-class capabilities from both open service providers and other organizations will create an increasingly fierce competitive climate for institutions of higher education, resulting in significant pressure on institutions to adopt a strategy of dynamic specialization. What Hegel and Brown call the "unbundling of corporations" (p. 60) we call the disaggregation of higher education. In order to resist this disassembling force, an institution will have to create and market a persuasive message about the value of learning at an institution that is, organizationally, entirely inward-looking.

Second, because open service providers will play central roles in facilitating future innovations, conventional universities and colleges must decide what role they desire to play in the evolution of higher education. (Ignoring this decision will significantly decrease their ability to proactively contribute to the conversation about the future of higher education.) If institutions want to exert a significant influence on the direction of higher education, they will likely need to become open service providers in order to maintain their central positions of influence. An institutional commitment to openness will be the ante necessary to sit at the innovation table. Institutions without some form of commitment to openness may be relegated to observer positions in which they cannot participate in creating significant innovations (because they have no meaningful open service to offer).

\section{Conclusion}

Openness is the fundamental value underlying significant changes in society and is a prerequisite to changes institutions of higher education need to make in order to remain relevant to the supersystem in which they exist. There are a number of ways institutions can be more open, 
including programs of open sharing of educational materials. Individual faculty can also choose to be more open without waiting for institutional programs. Increasing degrees of openness in society coupled with innovations in business strategy like dynamic specialization are enabling radical experiments in higher education and exerting increasing competitive pressure on conventional higher education institutions.

No single response to the changes in the supersystem of higher education can successfully address every institution's situation. However, every institution must begin addressing openness as an organizational value if it desires to both remain relevant to its learners and to contribute to the positive advancement of the field of higher education. 


\section{References}

ChaCha. (2009). ChaCha answers 150 million questions in 18 months. Retrieved from http://partners.chacha.com/2009/06/15/chacha-answers-150-million-questions-in-18months/.

Coase, R. (1937). The nature of the firm. Economica, 4(16), 386-405.

Coladarci T., \& Kornfield, I. (2007). RateMyProfessors.com versus formal in-class student evaluations of teaching. Practical Assessment, Research and Evaluation, 12(6). Retrieved from http://pareonline.net/getvn.asp?v=12\&n=6.

d'Oliveira, C. (2009). Why donate? Retrieved from http://ocw.mit.edu/OcwWeb/web/donate/invest/index.htm.

Eysenbach, G. (2006). Citation advantage of open access articles. PLoS Biol, 4(5), 157. doi:10.1371/journal.pbio.0040157

Fini, A., Formiconi, A., Giorni, A., Pirruccello, N., Spadavecchia, E., \& Zibordi, E. (2008). IntroOpenEd 2007: An experience on Open Education by a virtual community of teachers. Journal of e-Learning and Knowledge Society, 4(1), 231-239. Retrieved from http://www.je-lks.it/en/08_01/11Apfini_en.pdf.

Lovett, M., Meyer, O., \& Thille, C. (2008). The Open Learning Initiative: Measuring the effectiveness of the OLI statistics course in accelerating student learning. Journal of Interactive Media in Education. Retrieved from http://jime.open.ac.uk/2008/14.

Mott, J. (2009, July 24). Deja vu all over again - Blackboard still stuck in the innovator's dilemma. [Web log post]. Retrieved from http://www.jonmott.com/blog/2009/07/deja-vu-all-over-again-blackboard-still-stuck-inthe-innovators-dilemma/.

Robertson, J. (2009, September 9). Open education: Project or process and practice? [Web log post] Retrieved from http://blogs.cetis.ac.uk/johnr/2009/09/09/open-education-project-or-process-andpractice/.

McIntyre, D. A. (2009, March). The 10 most endangered newspapers in America. Time. Retrieved from http://www.time.com/time/business/article/0,8599,1883785,00.html.

Wesch, M. (2008). YouTube statistics. Retrieved from http://mediatedcultures.net/ksudigg/?p=163. 
Wiley, D. (2005, November 4). Content is infrastructure [Web log post]. Retrieved from http://opencontent.org/blog/archives/215.

Wiley, D. (2008, November 26). Content IS infrastructure (Welcome to the club, Chris) [Web log post]. Retrieved from http://opencontent.org/blog/archives/672.

Wiley, D. (2009, August 3). July BYU IS OCW update [Web log post]. Retrieved from http://opencontent.org/blog/archives/999.

1 Much has been written elsewhere about open access to research articles (e.g., Eysenbach, 2006). We mention this work for the sake of completeness, but the focus of this paper is on open access to educational resources. 